\title{
Visualising Trade-offs of Objectives in Omnichannel Management - A Mental Model Approach
}

\author{
Gültekin Cakir ${ }^{1}$ a \\ ${ }^{1}$ Innovation Value Institute, School of Business, Maynooth University, Maynooth, Ireland \\ gueltekin.cakir@mu.ie
}

Keywords: Omnichannel Management, Mental Models, Trade-offs, Channel Integration, Visualisation, Customer Experience.

Abstract: The retail industry is undergoing a major transformation process and retailers struggle in implementing a sustainable omnichannel strategy. For retailers, it is of crucial importance to achieve channel integration in order to generate a seamless customer experience. At the same time, balancing profitability while undergoing transition into omnichannel retailing poses a major challenge for many retail managers. These trade-offs can increase complexity and additional difficulties in decision-making. Mental models help to understand complex systems and behaviour and can support managers in decision-making processes. This paper proposes early work and an initial concept of a mental model arranging three critical objectives in omnichannel management: channel integration, customer experience generation, and economic value creation. Through a Venn Diagram approach, the relations between the objectives along with various scenarios of their achievements are illustrated, representing different states a retailer can undergo while following a transition towards omnichannel. Recommendations for actions are outlined for each scenario which can help retail managers to mentally depict dynamic relationships between objectives.

\section{INTRODUCTION}

With the dawn of the digitalisation of the retailing industry, the omnichannel phenomenon emerged and customers today shop across channels and expect a seamless customer experience (Hagberg et al., 2016; Grewal et al., 2017; Brynjolfsson et al., 2013; Verhoef et al., 2009; Verhoef et al., 2015).

However, for retailers, providing a seamless customer experience across all channels represents still a huge challenge (Hosseini et al., 2018). Channel integration is key to achieve omnichannel retailing and seamless transition across channels (Bijmolt et al., 2019). Following an omnichannel approach can be beneficial as studies show that channel integration is positively related to retail performance (Pauwels \& Neslin, 2015; Cao \& Li, 2015) - once realised.

While transitioning towards omnichannel retailing, decision-makers are required to balance the trade-offs in fulfilling customer-related as well as shareholder-value-related objectives (Gademann \& Brandt, 2016; Zhang et al., 2010).
Mental models help to understand complex system behaviour and can support decision-makers in making appropriate judgements and conclusions, especially for trade-off scenarios (Kaplan \& Norton, 1996a). This paper proposes the idea and initial concept of a visual mental model approach understanding the dynamic relationship and tradeoffs between omnichannel objectives. The aim is to develop a heuristic approach in aligning "Channel Integration", "Customer Experience Generation" and "Economic Value Creation" understood as critical objectives in achieving transition into omnichannel retailing.

With a Venn Diagram approach, various mechanics of the mental model are shown and implications for different scenarios discussed, giving potential practical guidance for retail managers for goal achievement towards omnichannel retailing.

Also, from an HCI perspective, visualisation via mental models can further contribute to the development of HCI systems (Li et al., 2016), relevant in the retailing sector.

https://orcid.org/0000-0001-9715-7167 
The rest of the paper is organised as follows. The next section outlines the basic understanding of "omnichannel retailing", the current phenomenon in the retailing industry, along with its critical objectives and the notion of trade-off relationships to consider. Thereafter, the concept of "mental models" is explained. The subsequent sections outline related work and the methodological approach, followed by the proposition of a conceptual mental model, visualised by Venn Diagrams. Descriptions along the visualisation with various mechanics and scenarios of the model are shown. Finally, the last section concludes the paper, stating limitations and future research of this work.

\section{BACKGROUND}

The following section describes the concept of omnichannel retailing along with its critical objectives as well as the notion of mental models.

\subsection{Omnichannel Retailing and Trade- offs in Objectives}

Omnichannel retailing refers to the concept of seamless and simultaneous use of all channels by customers (Shi, 2017). Verhoef defines the management of omnichannel retailing as "the synergetic management of the numerous available channels and customer touchpoints, in such a way that the customer experience across channels and the performance over channels is optimized." (Verhoef et al., 2015, p.176). For this, digital technologies such as smart mirrors, beacons, VR/AR, IoT, fog / edge computing (e.g. Mosquera et al., 2018; Iftikhar et al., 2019; Zimmermann et al., 2019); AI and AI applications (e.g. Cirqueira et al., 2019a; Cirqueira et al., 2019b; Mora et al., 2020) as well as consumer oriented concepts such as personalisation (e.g. Wetzlinger et al., 2017; Bielozorov et al., 2019) are leveraged.

Realising an omnichannel approach implies the ability to integrate and align all existing channels (Bijmolt et al., 2019; Zentes et al., 2016; Rigby, 2011). Channel integration is defined as the degree to which different channels interact with each other (Herhausen et al., 2015; Bendoly et al., 2005) in order to provide a seamless customer experience. This entails the integration on different levels such as organisation (Saghiri et al., 2017) or operations (assortment, inventory, pricing, logistics, etc.) (Zhang et al., 2010), representing a crucial objective to realise while undergoing omnichannel transformation.
Customer experience developed to the most critical aspect in the retail industry today (Brynjolfsson et al., 2013; Piotrowicz \& Cuthbertson, 2014; Verhoef et al., 2015) and represents the leading management objective (Lemon \& Verhoef, 2016) as well as is a strategic objective of non-financial nature (Cakir et al., 2019). It is defined as " $a$ multidimensional construct focusing on a customer's cognitive, emotional, behavioural, sensorial, and social responses to a firm's offerings during the customer's entire purchase journey ..." (Lemon \& Verhoef, 2016, p.71). It is of also crucial relevance for the development of competitive advantage (Kranzbühler et al., 2018).

Conflicting goals represent a trade-off problem where a decision-maker is confronted with trading off the realisation of one goal against another goal (Keeney \& Raiffa, 1993, Figure 1).

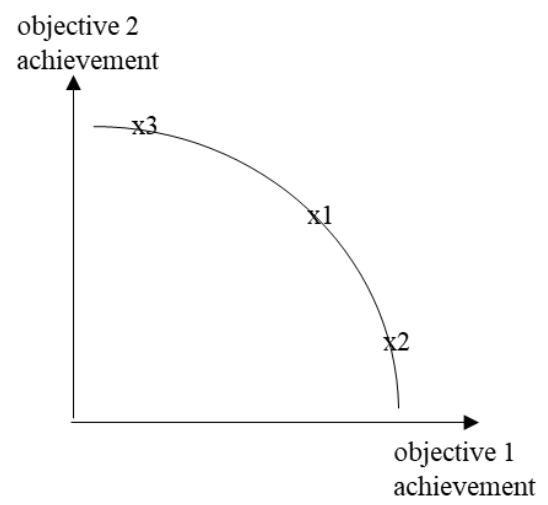

Figure 1: Trade-off-relation between two objectives (simplified, based on Keeney \& Raiffa, 1993).

Each decision (shown by $\mathrm{x}$ on the graph, Figure 1) depicts a trade-off situation where the degree of achievement of one objective is sacrificed against the achievement of the other objective.

The aspiration towards the realisation of an omnichannel strategy implies dealing with conflicting objectives. Meeting customer-related goals (represented by the objective "customer experience") can conflict with existing shareholdervalue-related business objectives (Gademann \& Brandt, 2016). Shareholder-value-related goals usually represent economic value creation and objectives of financial nature (e.g. profitability, return on investment). As the transition towards omnichannel retailing can pose significant shifts and realignment in resource allocation as well as drastic investments in digital technologies, overall profitability is stressed as a consequence (e.g. Zhang et al., 2010). 
Of course, conflicting goals are true for any business in general; however, in an omnichannel context, realising customer experience is of particular importance as the customer is the core of any activity out of an omnichannel strategy (Gademann \& Brandt, 2016). This is also evident through an increase in the role of "customer experience" as a concept of interest in recent retailing research (Cakir et al., 2019). More importantly in this context, "channel integration" is key to align the above-mentioned objectives. The assumption is, once channel integration is achieved, superior customer experience along all channels can be realised (e.g. Herhausen et al., 2015), postulating a positive relationship between these objectives.

\subsection{Mental Models}

Mental models can be understood as mental representations of external systems that are used by individuals (e.g. managers) in order to describe, explain, and predict behaviour of those systems (Johnson-Laird, 1983). They are of subjective nature and intend to support a decision-maker's judgements and decisions (Markman, 2013; Markman \& Gentner, 2001) as they are created and adjusted through interactions with real business systems (e.g. business operations) they manage (Capelo \& Dias, 2009). They, therefore, involve assumptions and expectations based on experience and knowledge on system behaviour (Kaplan \& Norton, 1996; Lant et al., 1992). Meadows et al. state that "each person carries in his head a mental model, an abstraction of all his perceptions and experiences in the world, which he uses to guide his decisions..." (Meadows et al., 1974, pp. 4-5). Mental models are also used in the context of teamwork and team performance. The idea represents the ability to predict team member behaviour and needs in order to improve coordination and decision-making (e.g. Denzau \& North, 2000; Converse et al., 1993).

A well-known exemplary mental model is the "Circle of Competence" developed by Warren Buffet and Charlie Munger (Figure 2). With the help of an Euler Diagram, the visualisation differentiates between an inner circle "What you know" and an outer circle "What you think you know" in an investment context (Street, 2013). The concept aims to show the boundaries of one's own competence to realise the limits in decision-making ("only invest in those things you know about"). The idea is to respect your own boundaries and make investment decisions according to your knowledge sphere and not to follow "what you think you know".



Figure 2: "Circle of Competence" mental model.

\section{RELATED WORK}

Literature addressing the tension between achieving different objectives while undergoing omnichannel transition is scarce. Nevertheless, several studies contribute to the discourse from different perspectives. The following provides an outline of the most relevant studies.

For example, Kumar et al. (2017) propose a framework aligning strategies and actions from a market, firm, store, and customer perspective, influencing the overall objective "retailer profitability". Although not explicitly discussing objectives and their relationships, the study shows "customer experience" as a strategic aspect affecting the overall objective "retailer profitability". Furthermore, the study is not specifically demonstrating an omnichannel emphasise but covers the notion from a higher industry level. Through a qualitative grounded theory approach, Cao \& $\mathrm{Li}$ (2015) find out that cross-channel integration stimulates sales-growth. However, a customer experience perspective is left out. The study by Oh et al. (2012) relate channel integration (enabled by IT) to firm performance and takes into account human resources. Empirically grounded findings postulate a positive relationship and underline efficient offering delivery and innovativeness in future offering creation. However, customer experience is not addressed explicitly, and the context can be regarded as pre-omnichannel / cross-channel.

\section{METHODOLOGY}

The concept of Venn Diagrams is used to visualise the mental model, along with shared and overlapping sections (Venn, 1880). Three circles represent the above-outlined concepts 
- Channel Integration (CI)

- Economic Value (EV) Creation and

- Customer Experience (CX) Generation, resembling the three critical management objectives to realise a sustainable omnichannel strategy (Table $1)$.

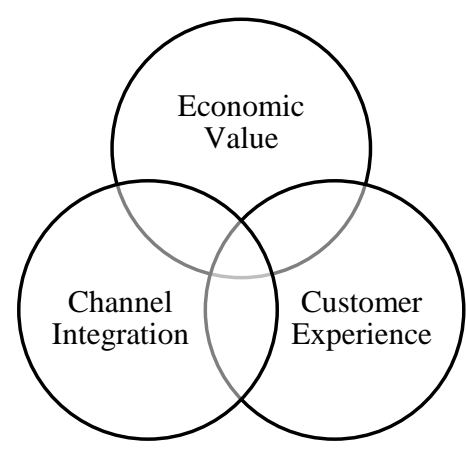

Figure 3: Mental model visualised as a Venn Diagram.

The intersections depict the relationship between the concepts of the model. The larger the overlap the more complementary the two objectives are to each other, reflecting their positive relationship (Figure 3).

Table 1: Description of omnichannel objectives.

\begin{tabular}{|l|l|}
\hline Objective & Description \\
\hline $\begin{array}{l}\text { Channel } \\
\text { Integration }\end{array}$ & $\begin{array}{l}\text { This objective is realised when } \\
\text { channels are integrated in such a } \\
\text { way that alignment and interaction } \\
\text { among these are ensured and } \\
\text { operational. Realisation is driven } \\
\text { through investments in e.g. digital } \\
\text { technologies, restructuring efforts, } \\
\text { or acquisition of relevant know- } \\
\text { how. }\end{array}$ \\
\hline $\begin{array}{l}\text { Customer } \\
\text { Generience }\end{array}$ & $\begin{array}{l}\text { This objective is realised when a } \\
\text { seamless transition along the } \\
\text { customer journey across all } \\
\text { available channels is ensured for } \\
\text { the customer. Reflects customer- } \\
\text { oriented objectives. }\end{array}$ \\
\hline $\begin{array}{l}\text { Economic } \\
\text { Value } \\
\text { Creation }\end{array}$ & $\begin{array}{l}\text { This objective is realised when the } \\
\text { retailer is able to generate financial } \\
\text { value (e.g. profitability). Reflects } \\
\text { shareholder-value objectives. }\end{array}$ \\
\hline
\end{tabular}

E.g. a high overlap of channel integration and customer experience depicts a strong positive relationship ("the realisation of channel integration relates to the generation of customer experience"). Theoretically, full overlap, evident by fully congruent circles, would reflect a perfect harmonic relationship between all three objectives.

For the approach in this study, trade-off relationships are considered under certainty to simplify and eliminate uncertain consequences (Keeney \& Raiffa, 1993). Furthermore, in line with the subjective nature of a mental model (Markman, 2013; Markman \& Gentner, 2001), the concept follows a non-formalized approach (Keeney \& Raiffa, 1993) because of the same reason.

The underlying theory is provided by Gross et al. (2016), which is based on the Attention-Based View of the firm (Ocasio, 1997). The study discusses founders' mental models (and cognitive boundaries) and how they influence business model configuration / innovation based on the specific decisions the individuals make. For this, the authors decompose the business model configuration into components (customer value proposition, resources and capabilities and economic logic) and reflect their mechanics for business model configuration (Figure 4).

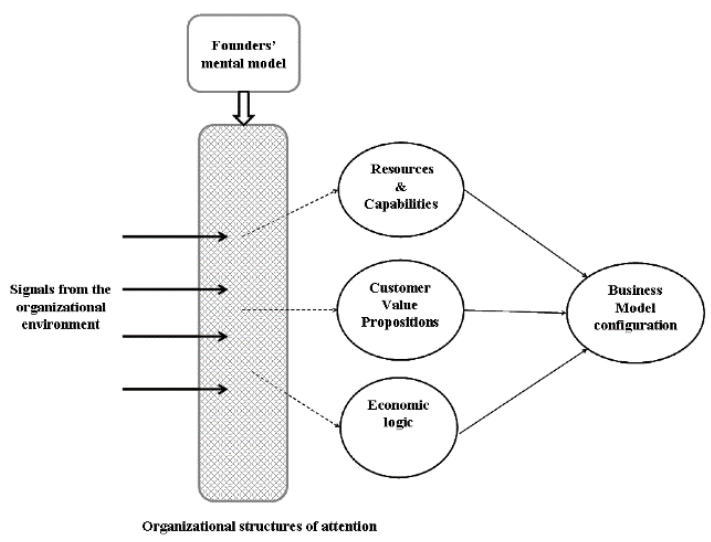

Figure 4: Mental Models for Business Model Configuration (Gross et al., 2016).

\section{MENTAL MODEL VISUALISING OMNICHANNEL MANAGEMENT OBJECTIVES}

The mental model can reflect five basic constellations and scenarios a manager might be confronted with while pursuing an omnichannel approach.

\section{(1) High CX Generation / Low EV Creation}

This scenario shows the positive relationship between the objectives CI and CX (Figure 5). However, EV is 
not or barely achieved. This mental model constellation can represent scenarios in which a retailer is achieving a distinct customer experience through effective channel integration but fails to stay profitable while doing so. The priority lies in the customer experience generation and thus can represent retailers who are customer-centric and follow a strong customer-oriented strategy. This is in line with the omnichannel principle in aligning all channels in order to generate positive customer experience (e.g. Verhoef et al., 2015).

Here, it is recommended to exploit the high CX achievement and translate the value created to financial impact. In addition, improving costeffectiveness for CI activities can further increase the achievement of EV goals.

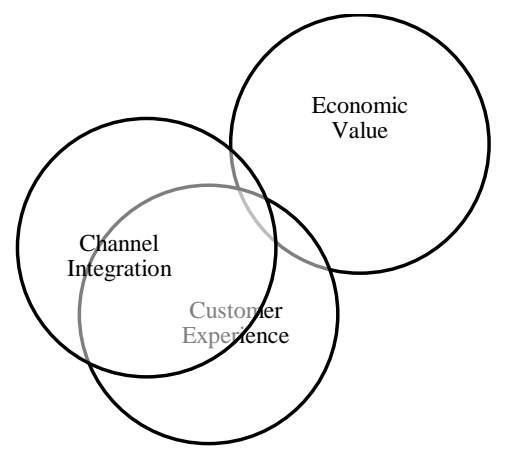

Figure 5: High CX Generation / Low EV Creation.

\section{(2) High EV Creation / Low CX Generation}

In this constellation, there is a positive relationship between the realisation of $\mathrm{CI}$ and the objective EV. However, no substantial CX generation is achieved (Figure 6). Here, ineffective channel integration efforts are made making the business profitable but failing at generating important CX. This might be explained by ineffective but cost-effective CI measures that favour meeting profitability goals over CX goals.

The recommended action here is coordinating channel integration activities towards CX (effective $\mathrm{CI}$ ) as well as considering investing in more $\mathrm{CI}$ activities. Prioritising $\mathrm{CX}$ over EV while doing so represents the appropriate rationale and direction in achieving omnichannel transition.

Furthermore, it should be noted that this constellation cannot be of sustainable nature if there are no long-term investments towards CX generation made as the industry and competition follows the trend in providing a distinctive customer experience. This constellation and constellation (1) represent the typical trade-off problem current retailers are faced with.

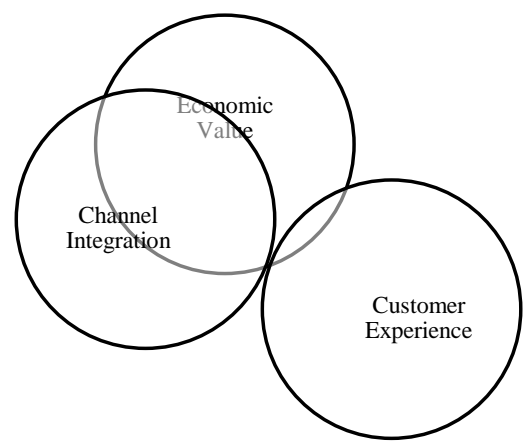

Figure 6: High EV Creation / Low CX Generation.

\section{(3) Low CX Generation / Low EV Creation}

This scenario can be described as a pre-omnichannelstage as CI is not fulfilled as well as there is no CX generation. As a result, no substantial EV is created (Figure 7)

In this scenario, the business is deemed to fail in achieving any critical objective and should reconsider the current strategy immediately. It is recommended to drive $\mathrm{CI}$ activities to generate $\mathrm{CX}$.

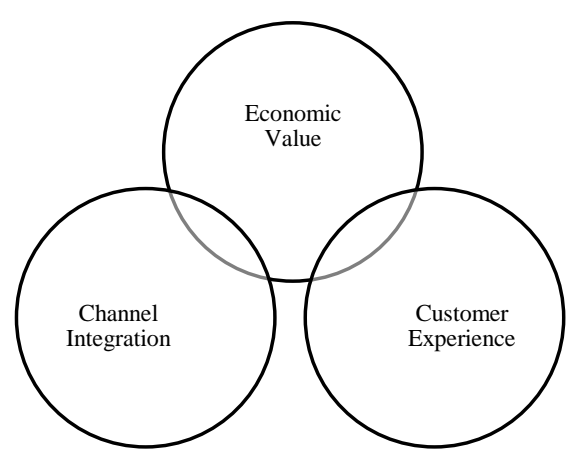

Figure 7: Low CX Generation / Low EV Creation.

\section{(4) High CX Generation / High EV Creation but no CI achievement}

In this scenario, the business generated high $\mathrm{CX}$ and is profitable at the same time (high EV creation). However, this is a result of no CI activities as channel integration is not achieved (Figure 8).

This constellation can depict scenarios in which retailers provide a high $\mathrm{CX}$ without following an omnichannel approach with integrated channels. In those cases, it is important to realise that this strategy 
does not lie on a sustainable ground as competition successively follows an integrated approach, and sooner or later the retailer will fall back (customers will turn towards integrated retailers and EV will drop eventually). It is recommended to make use of the high EV output and make sustainable investments in CI activities.

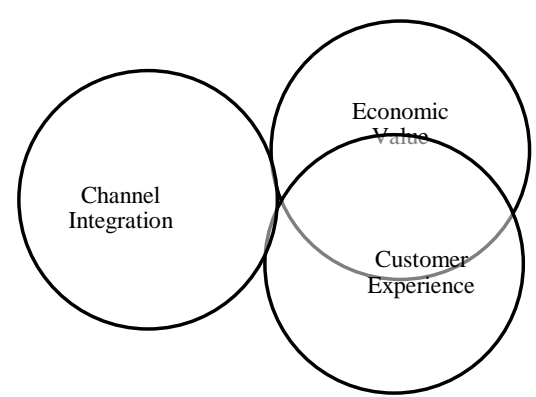

Figure 8: High CX Generation / High EV Creation but no CI achievement.

\section{(5) Towards Omnichannel Approach}

The intersection between all three objectives represents a balanced constellation, harmonizing all three objectives. Achieving CI leads to the generation of high CX and high EV creation at the same time (Figure 9). CI activities are effective. It represents the ideal scenario and serves as a mental aspiration.

Once achieved, it is recommended to keep this constellation and optimise further the balance between the objectives. This scenario reflects a successful direction towards a sustained omnichannel approach.

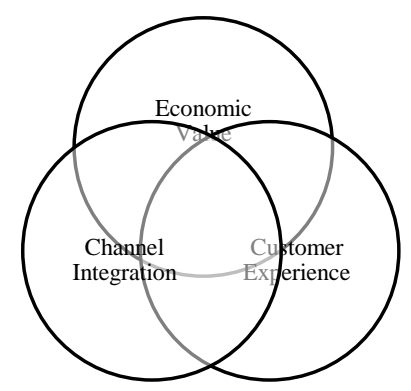

Figure 9: Towards Omnichannel Approach.

The above-mentioned scenarios reflect a possible setting while undergoing omnichannel transformation. Especially, it is shown that the mental model is able to
- depict relevant and critical objectives in realising an omnichannel strategy,

- support decision-makers in realising the trade-off relationships between those objectives, and

- support decision-makers in realising implications of certain scenarios and understand possible actions to overcome shortcomings in their current state.

\section{CONCLUSIONS}

The challenge in realising an omnichannel strategy is of major relevance for current retailers and demand an understanding of trade-off relationships between critical objectives. This paper proposes an initial idea of utilising a mental model approach, relating the omnichannel management objectives "Channel Integration", "Customer Experience Generation" and "Economic Value Generation" and visualising different dynamics and scenarios in their achievements. With this, retail managers are able to reflect the need for balancing financial and nonfinancial objectives, realise the trade-offs while achieving one objective or the other, and understand and predict certain scenarios with the aim to act towards omnichannel realisation.

This short paper is an early work and involves the following limitations. It represents an initial idea and is subject to be further developed. Currently, there is no validation as the concept requires to be evaluated by empirical means such as case studies. Another limitation is given by the fact that the proposed constellations of the mental model are not covering all relevant scenarios. More elaboration would also be necessary regarding the time perspective: e.g. how do those scenarios relate to each other from a time perspective? Additionally, reflecting upon an HCI application perspective can further help to contribute to the field and eventually develop towards a potential instantiation (e.g. scorecard tool).

\section{ACKNOWLEDGEMENTS}

This project has received funding from the European Union's Horizon 2020 research and innovation programme under the Marie SkłodowskaCurie grant agreement No. 765395, and was also supported, in part, by Science Foundation Ireland grant 13/RC/2094 and co-funded under the European Regional Development Fund through the 
Southern \& Eastern Regional Operational Programme to Lero -the Irish Software Research Centre (www.lero.ie).

\section{REFERENCES}

Bendoly, E., Blocher, J. D., Bretthauer, K. M., Krishnan, S., \& Venkataramanan, M. A. (2005). Online/in-store integration and customer retention. Journal of Service Research, 7(4), 313-327.

Bielozorov, A., Bezbradica, M., \& Helfert, M. (2019, July). The role of user emotions for content personalization in e-commerce: literature review. In International Conference on Human-Computer Interaction (pp. $177-$ 193). Springer, Cham.

Bijmolt, T. H., Broekhuis, M., De Leeuw, S., Hirche, C., Rooderkerk, R. P., Sousa, R., \& Zhu, S. X. (2019). Challenges at the marketing-operations interface in omni-channel retail environments. Journal of Business Research.

Brynjolfsson, E., Hu, Y. J., \& Rahman, M. S. (2013). Competing in the age of omnichannel retailing (pp. 17). Cambridge, MA: MIT.

Cakir, G., Bezbradica, M., \& Helfert, M. (2019, June). The Shift from Financial to Non-financial Measures During Transition into Digital Retail-A Systematic Literature Review. In International Conference on Business Information Systems (pp. 189-200). Springer, Cham.

Cao, L., \& Li, L. (2015). The impact of cross-channel integration on retailers' sales growth. Journal of Retailing, 91(2), 198-216.

Capelo, C., \& Dias, J. F. (2009). A system dynamics based simulation experiment for testing mental model and performance effects of using the balanced scorecard. System Dynamics Review: The Journal of the System Dynamics Society, 25(1), 1-34.

Cirqueira, D., Helfert, M., \& Bezbradica, M. (2019, September). Towards Preprocessing Guidelines for Neural Network Embedding of Customer Behavior in Digital Retail. In Proceedings of the 2019 3rd International Symposium on Computer Science and Intelligent Control (pp. 1-6).

Cirqueira, D., Hofer, M., Nedbal, D., Helfert, M., \& Bezbradica, M. (2019, September). Customer Purchase Behavior Prediction in E-commerce: A Conceptual Framework and Research Agenda. In International Workshop on New Frontiers in Mining Complex Patterns (pp. 119-136). Springer, Cham.

Converse, S., Cannon-Bowers, J. A., \& Salas, E. (1993). Shared mental models in expert team decision making. Individual and group decision making: Current issues, 221, 221-46.

Denzau, A. T., \& North, D. C. (2000). Shared mental models: ideologies and institutions. Elements of reason: Cognition, choice, and the bounds of rationality, 23-46.

Gademann, N., \& Brandt, G. (2016): Omni-channel Strategy. In Van Woensel, Broft: Omni Channel Logistics - state of the art.
Grewal, D., Roggeveen, A. L., \& Nordfält, J. (2017). The Future of Retailing. Journal of Retailing, 93(1), 1-6.

Gross, N., McNamara, P., Ryazanova, O., \& Connolly, N. (2016). Integrative or Autonomous? Mental Models and Experimentation-Driven Business Model Innovation. In Academy of Management Proceedings (Vol. 2016, No. 1, p. 15886). Briarcliff Manor, NY 10510: Academy of Management.

Hagberg, J., Sundström, M., \& Nicklas, E. Z. (2016). The digitalization of retailing: an exploratory framework. International Journal of Retail \& Distribution Management, 44(7), 694-712.

Herhausen, D., Binder, J., Schoegel, M. and Herrmann, A., 2015. Integrating bricks with clicks: retailer-level and channel-level outcomes of online-offline channel integration. Journal of retailing, 91(2), pp.309-325.

Hosseini, S., Merz, M., Röglinger, M., \& Wenninger, A. (2018). Mindfully going omni-channel: An economic decision model for evaluating omni-channel strategies. Decision Support Systems, 109, 74-88.

Iftikhar, R., Pourzolfaghar, Z., \& Helfert, M. (2019). Omnichannel Value Chain: Mapping Digital Technologies for Channel Integration Activities.

Johnson-Laird, P. N. (1983). Mental models: Towards a cognitive science of language, inference, and consciousness (No. 6). Harvard University Press.

Kaplan, R. S., \& Norton, D. P. (1996). Translating strategy introduction the balanced scorecard. Harvard Business School.

Keeney, R. L., \& Raiffa, H. (1993). Decisions with multiple objectives: preferences and value trade-offs. Cambridge university press.

Kranzbühler, A. M., Kleijnen, M. H., Morgan, R. E., \& Teerling, M. (2018). The multilevel nature of customer experience research: an integrative review and research agenda. International Journal of Management Reviews, 20(2), 433-456.

Kumar, V., \& Reinartz, W. (2016). Creating enduring customer value. Journal of Marketing, 80(6), 36-68.

Kumar, V., Anand, A., \& Song, H. (2017). Future of retailer profitability: An organizing framework. Journal of Retailing, 93(1), 96-119.

Lant, T. K., Milliken, F. J., \& Batra, B. (1992). The role of managerial learning and interpretation in strategic persistence and reorientation: An empirical exploration. Strategic management journal, 13(8), 585-608.

Lemon, K. N., \& Verhoef, P. C. (2016). Understanding customer experience throughout the customer journey. Journal of marketing, 80(6), 69-96.

Li, K., Tiwari, A., Alcock, J., \& Bermell-Garcia, P. (2016). Categorisation of visualisation methods to support the design of Human-Computer Interaction Systems. Applied ergonomics, 55, 85-107.

Markman, A. B. (2013). Knowledge representation. Psychology Press.

Markman, A. B., \& Gentner, D. (2001). Thinking. Annual review of psychology, 52(1), 223-247.

Meadows, D. L., Behrens, W. W., Meadows, D. H., Naill, R. F., Randers, J., \& Zahn, E. (1974). Dynamics of 
growth in a finite world (p. 637). Cambridge, MA: Wright-Allen Press.

Mithas, S., Krishnan, M. S., \& Fornell, C. (2016). Research note-Information technology, customer satisfaction, and profit: Theory and evidence. Information Systems Research, 27(1), 166-181.

Mora D., Jain S., Nalbach O., Werth D. (2020). An In-store Recommender System Leveraging the Microsoft HoloLens. In: Stephanidis C., Antona M. (eds) HCI International 2020 - Posters. HCII 2020. Communications in Computer and Information Science, vol 1225. Springer, Cham.

Mosquera, A., Olarte-Pascual, C., Ayensa, E. J., \& Murillo, Y. S. (2018). The role of technology in an omnichannel physical store. Spanish Journal of Marketing-ESIC.

Ocasio, W. (1997). Towards an attention - based view of the firm. Strategic management journal, 18(S1), 187206.

Oh, L. B., Teo, H. H., \& Sambamurthy, V. (2012). The effects of retail channel integration through the use of information technologies on firm performance. Journal of operations management, 30(5), 368-381.

Pauwels, K., \& Neslin, S. A. (2015). Building with bricks and mortar: The revenue impact of opening physical stores in a multichannel environment. Journal of Retailing, 91(2), 182-197.

Piotrowicz, W., \& Cuthbertson, R. (2014). Introduction to the special issue information technology in retail: Toward omnichannel retailing. International Journal of Electronic Commerce, 18(4), 5-16.

Rigby, D. (2011). The future of shopping. Harvard business review, 89(12), 65-76.

Saghiri, S., Wilding, R., Mena, C., \& Bourlakis, M. (2017). Toward a three-dimensional framework for omnichannel. Journal of Business Research, 77, 53-67.

Shi, F. (2017). Omni-Channel Retailing: Knowledge, Challenges, and Opportunities for Future Research. In Marketing at the Confluence between Entertainment and Analytics (pp. 91-102). Springer, Cham.

Street, F. (2013). The 'Circle Of Competence' Theory Will Help You Make Vastly Smarter Decisions. Business Insider. Retrieved from https://www.businessinsider.com/the-circle-ofcompetence-theory-2013-12? $\mathrm{r}=\mathrm{DE} \& \mathrm{IR}=\mathrm{T}$.

Venn, J. (1880). I. On the diagrammatic and mechanical representation of propositions and reasonings. The London, Edinburgh, and Dublin philosophical magazine and journal of science, 10(59), 1-18.

Verhoef, P. C., Lemon, K. N., Parasuraman, A., Roggeveen, A., Tsiros, M., \& Schlesinger, L. A. (2009). Customer experience creation: Determinants, dynamics and management strategies. Journal of retailing, 85(1), 31-41.

Verhoef, P. C., Kannan, P. K., \& Inman, J. J. (2015). From multi-channel retailing to omni-channel retailing: introduction to the special issue on multi-channel retailing. Journal of retailing, 91(2), 174-181.

Wetzlinger, W., Auinger, A., Kindermann, H., \& Schönberger, W. (2017, July). Acceptance of personalization in omnichannel retailing. In
International Conference on HCI in Business, Government, and Organizations (pp. 114-129). Springer, Cham.

Zentes, J., Morschett, D., \& Schramm-Klein, H. (2007). Strategic retail management. Betriebswirtschaftlicher Verlag Dr. Th. Gabler GWV Fachverlage $\mathrm{GmbH}$, Wiesbaden (GWV).

Zhang, J., Farris, P. W., Irvin, J. W., Kushwaha, T., Steenburgh, T. J., \& Weitz, B. A. (2010). Crafting integrated multichannel retailing strategies. Journal of Interactive Marketing, 24(2), 168-180.

Zimmermann, R., Auinger, A., \& Riedl, R. (2019, July). Smartphones as an Opportunity to Increase Sales in Brick-and-Mortar Stores: Identifying Sales Influencers Based on a Literature Review. In International Conference on Human-Computer Interaction (pp. 8298). Springer, Cham. 